Chiara Ambrosio - Unsettling Robots and the Future of Art Science, Vol. 365, Issue 6448, pp. 38-39

Please cite from the published version. Also available open access at: https://blogs.sciencemag.org/books/2019/07/01/unsecured-futures/

\title{
Unsettling Robots and the Future of Art
}

\author{
Chiara Ambrosio \\ Department of Science and Technology Studies \\ UCL \\ c.ambrosio@ucl.ac.uk
}

My train ride from London to Oxford is filled with anticipation. Having just watched the latest season of Black Mirror, I anticipate the same blending of wit, unintended consequences, and dystopian paradox from the new exhibition that has just opened at the Barn Gallery in St John's College, Oxford.

Unsecured Futures is the solo show of the first ultra-realistic humanoid robot artist, Ai-Da. A versatile artist, Ai-Da dabbles in drawing and painting as well as sculpture and performance. "She" is the result of a large multi-disciplinary team that features artists, curators, computer scientists from the universities of Oxford and Leeds, and Cornwall-based company Engineering Arts Ltd. The press release feeds my sense of expectation, promising me that she is absolutely unique: "Ai-Da's ability as a robot to draw and paint from sight has never been achieved before and makes Ai-Da an artist in her own right, as well as a world first."

As I enter the gallery space, the exhibition synopsis advises that Ai-Da produces art "but she is also the art herself, highlighting tensions of trans-humanism [sic], biotechnological advances, and how we will come to redefine our views of creativity." And there is more: Ai-Da aims to raise questions on a host of pressing social issues, ranging from how "necessary ethical discussions" about technology are "painfully lagging behind," to addressing "the frailty of our environment." The text concludes with a nod to George Orwell, Aldous Huxley and Aleksandr Solzhenitsyn.

In three corners of the gallery, large screens show close-ups of Ai-Da performing her Poetry of Consolation, based on the prison literature of Fyodor Dostoyevsky, Oscar Wilde and Severinus Boethius. The artwork label, a printed A4 sheet of paper blue-tacked to the wall and typed in 12-point font, cryptically explains that the original texts are used "as the input data for AI algorithms based on Markov chains." It then swiftly moves to draw comparisons between prison literature and "the pain and suffering of animals housed in unsuitable captive environments." Along one of the gallery walls, Ai-Da's pencil portraits of Charles Babbage, Alan Turing, Ada Lovelace (the robot's namesake), Karel Čapec, Leonardo da Vinci, and her own self portrait are hung side by side - inscribing Ai-Da in the long history of creativity, computing and invention.

Ai-Da's paintings are the most visually spectacular items on display. Rich tones of red, yellow and green, and thick brushstrokes suggest a human touch. The position of the lights draws the viewer's gaze right to the center of each work, heightening the "shattered" composition of the abstract paintings. Labels state that coordinates from Ai-Da's drawings, are "plotted onto the Cartesian plane and then run through AI algorithms." The digital versions of the artworks were transferred on canvas and overlaid with oil painting by artist Suzie Emery.

On the train home I cannot stop thinking about the paintings. How are neural networks "trained" to obtain them? How does Ai-Da choose the color of her artworks? My questions are interrupted by an email from the exhibition's press office, who kindly put me in contact with the Oxford-based computer scientist behind the paintings, Aidan Gomez. In a clear and detailed email, he explains how he uses logs of Ai-Da's motor instructions to wire the large neural network that creates the foundational design for the paintings. He tells me that he chooses the color palette, clarifying however that "it is the network's responses that dictate which colour lands at each point on the canvas, the lightness, the intensity, and so forth." He shares digital proofs, which provide an exciting glimpse at what the images look like before they are transferred on canvas and overlaid with paint. He stresses that Emery's artistic input is the decisive factor in the final form of the paintings.

Gomez's clear answers remain overshadowed - in the exhibition as well as in the press - by the hype around a female-presenting robot who produces original art. On my return home, I turn on the television and there is Ai-Da, with her flamboyant creator, Aidan Meller. As Ai-Da quietly draws, Meller makes bold statements about ethics in the digital age, and how we need to re-think creativity. A welcome reference to philosopher Margaret Boden creeps in, but remains unexplained.

We need public engagement, he continues. But thus far, the appearance of Ai-Da has produced exactly the opposite effect: a cacophony of fashionable terms that will alienate a non-academic audience and infuriate an academic one. We are already asking big questions about technology, and about algorithms in particular. Virginia Eubanks' Automating Inequality, Safiya Umoja Noble's Algorithms of Oppression, Cathy O'Neal's Weapons of Math Destruction, albeit not concerned with art in the digital age, are only a few examples of how technology does not only need to be questioned - it needs to be questioned rigorously and unpretentiously. 
Chiara Ambrosio - Unsettling Robots and the Future of Art Science, Vol. 365, Issue 6448, pp. 38-39

Please cite from the published version. Also available open access at: https: / /blogs.sciencemag.org/books/2019/07/01/unsecured-futures/

That mysterious algorithms and a random list of social issues live separate lives in the dazzling space of Unsecured Futures is a worrying sign of what can happen when a narrow conception of art joins the hype around AI and its applications. "Tensions of transhumanism", "ethics" and "public engagement" become empty terms, waved for effect and never probed. The result is an overload of information that polarizes opinion, fosters divides, and obliterates the critical potential of art as research in its own right.

As a philosopher, part of my job is to articulate questions that will take us beyond shallow slogans and commonplace assumptions. I found depth in Suzie Emery's brushstrokes, which compelled me to ask how Ai-Da's paintings came to be. I found depth in Aidan Gomez's honest answers about the uncertainties surrounding color processing in a neural network. I am certain that other collaborators, overshadowed by the lights of press conferences and television interviews, have equally interesting stories to tell.

Giving more space to the "how" of art and science is difficult and time consuming. It requires investigating the details. But only when this component is brought to the fore can we begin articulating interesting questions about our relationship with technology. 